\title{
PENELITIAN KOMPOSISI KIMIA, JENIS BAHAN MENTAH DAN KUALITAS PASTA KAPUR UNTUK PROSES "LIMING"
}

Oleh : Koentoro Soebijarso *

Abstract

The ain of this research was to determine the chemical composition, kind of raw material and the quality of paste of lime-water, for liming process in the limevard within a tannery. Paste of lime water was produced by adding a quantity of water to lime in the pit. Samples was taken from the pits, after the hydration reaction was completed.The lime-paste was immersed in water to avoid natural carbonization reaction with carbondioxide in the air The samples paste lime-water soon analysed. It was concluded that the paste of lime-water composed mainly of $12.75 \% \mathrm{CaO}$ and $15.81 \% \mathrm{MgO}$ wet basis. The $\mathrm{pH}$ of the saturated limewater solution was 12.5. The raw material used was dolomite limestone. The quality of paste of lime-water was suitable for liming process.

\section{ABSTRAK}

Tujuan dari penelitian ini adalah untuk menetapkan susunan kimia,jenis bahan mentah dan kualitas pasta kapur, untuk proses pengapuran di bagian pengapuran dalam industri penyamakan kulit. Pasta kapur dihasilkan dengan menambahkan sejumlah air ke kapur tohor dalam bak. Contoh-contoh diambil dari bak-bak, setelah reaksi hidrasi selesai dengan sempurna Pasta kapur telah direndam dalam air untuk mencegah reaksi karbonisasi alamiah dengan karbondioksida di udara.Contoh-contoh pasta kapur segera dianalisa.Telah disimpulkan bahwa pasta kapur tersusun utamanya dari $\mathrm{CaO}$ 12,75\% dan $\mathrm{MgO}$ 15,81\% atas dasar bahan basah.pH dari larutan jenuh larutan kapur dalam air adalah 12,5. Bahan mentah yang digunakan adalah batu kapur dolomitis. Mutu dari pasta kapur telah memenuhi syarat untuk proses pengapuran.

\section{PENDAHULUAN}

Proses pengapuran (liming process) pada tahap pengerjaan basah di "beamhouse" merupakan perlkuan lanjutan setelah proses perendaman/pencucian kulit mentah dan bagian awal dari keseluruhan rangkaian proses penyamakan kulit untuk memproduksi kulit (leather manufacturing). Secara garis besar keseluruhan proses dapat dikatakan : pre-tanning $\longrightarrow$ tanning $\longrightarrow$ post tanning.Kapur yang digunakan dalam proses liming adalah jenis kapur tohor atau kapur mati (Quiclime or hydrated lime). Jika digunakan kapur tohor maka haruslah dilakukan pengerjaan pendahulun dengan proses penambahan sejumlah air, setelah proses telah selesai maka akan terdapat pasta kapur, yang harus terrendam dalam air untuk mencegah

*) PNS pada BBKKP 
proses karbonisasi. Penelitian ini bertujuan untuk mengetahui komposisi kimia, jenis bahan mentah yang digunakan serta kualitas dari pasta kapur yang digunakan untuk proses pengapuran kulit mentah. Diperkirakan bahwa kapur tohor yang diproses menjadi pasta kapur ini yang berasal dari batuan kapur dapat memenuhi syarat untuk keperluan pabrik penyamakan kuliut. Batuan kapur di Indonesia terdapat secara melimpah.

\section{TINJAUAN PUSTAKAAN DAN LAPANGAN}

Bahan mentah yang digunakan untuk pembuatan kapur tohor berasal dari proses pembakaran batuan kapur,kalsit $\left(\mathrm{CaCO}_{3}\right)$, batu kapur dolomit, mergel, dll Batuan kapur dengan komposisi kalsium karbonat murni setelah mengalami proses dekarbonisasi dapat digunakan untuk pembuatan pasta kapur, melalui proses hidrasi. namun secara teknis-ekonomis tidak dibuat untuk tujuan pemakaian di industri penyamakan kulit. Pada umumnya batuan kapur yang dibakar menjadi kapur tohor selain terdiri dari kalsiumkarbonat, $\mathrm{CaCO}_{3}$, juga terdapat pula unsur dan senyawa lainnya seperti, Magnesium, Besi, Aluminium, Silikat, dll. Untuk keperluan proses pembakaran batuan kapur diperlukan kandungan $\mathrm{CaCO}_{3}$ dan $\mathrm{MgCO}_{3}$ minimal $50 \%$ (Ulman,3.A brennen des Kalkes).Pada proses pembakaran batuan kapur terjadi disintegrasi Kalsiumkarbonat sebagai persamaan berikut ini

$$
\mathrm{CaCO}_{3} \longrightarrow \mathrm{CaO}+\mathrm{CO}_{2} \quad \mathrm{H}=+396 \mathrm{kal} / \mathrm{g} .
$$

Proses kalsinasi yang dapat balik ini pada suhu 1000 - $1200 \mathrm{C}$ akan berjalan ke kanan dan menghasilkan Kalsiumoksida, CaO(Ullman,3.A seite 242-247).

Untuk keperluan proses pengapuran kulit mentah, maka hasil dari pembakaran batuan kapur yang disebut kapur tohor, tidak secara langsung digunakan,mesti dilaksanakan hidrasi terlebih dahulu. Hasil hidrasi dapat berbentuk kapur mati atau "hydrated lime" yang dipasarkan dalam kantong-kantong kertas sekali pakai.Atau sistem yang lainnya dengan membuat pasta kapur.Jenis pasta kapur inilah yang menjadi bahan penelitian ini.Adapun reaksi hidrasi berjalan sebagai berikut :

$$
\mathrm{CaO}+\mathrm{H}_{2} \mathrm{O} \longrightarrow \mathrm{Ca}(\mathrm{OH})_{2} \quad \mathrm{H}=-15,6 \mathrm{k} \mathrm{cal} .
$$

Kalsiumoksida mempunyai kelarutan di dalam air dalam jumlah yang kecil,yaitu sebesar 1,3 gram dalam setiap liter air pada suhu kamar, dan kelarutannya akan menurun pada peningkatan suhu( H.Herfeld). Adapun pasta kapur yang menjadi topik penelitian ini dibuat dengan cara hidrasi kapur tohor di dalam bak, sehingga terbentuk pasta kapur;pasta kapur ini harus terendam didalam air, agar supaya tidak terjadi reaksi dengan gas $\mathrm{CO}_{2}$ yang terdapat diudara.
Secara teoritis maka setiap gram kapur tohor memerlukan 32,14 liter air, berdasarkan reaksi tersebut diatas. (G.Mauthe,"Chemie fur den Gerber", seite 27.) Didalam praktek maka penambahan air sebanyak 3 sampai 6 kali lebih banyak dari kebutuhan teoritis tersebut.

Hans Herfeld,Dr.,ING., menyimpulkan bahwa pada $\mathrm{pH}$ 12,5 bakteri akan terbunuh dan tidak berkembang biak,sedangkan Wilson J.A.,Sc.D. menyatakan bahwa pada $\mathrm{pH}=12,5$ yaitu keadaan dimana larutan kapur jenuh semua bakteri akan terbunuh, sedangkan pada ph 8 - 10 adalah merupakan daerah optimal kerja dari mikroba proteolitik.

Penelitian lapangan menunjukkan bahwa baik "hydrated lime" maupun pasta kapur yang secara khusus dibuat oleh Penyamak, maupun kapur mati (kapur yang telah disiram air, istilah yang dipergunakan oleh W.J.S. Poerwodarminto) dalam bentuk curai. digunakan untuk proses pengapuran. Umumnya proses kapur sulfida digunakan dalam liming, sekaligus untuk buang bulu.

Demikian pula dalam kegiatan $\mathrm{R}+\mathrm{D}$ juga menggunakan salah satu jenis kapur tersebut untuk keperluan pengapuran dan atau proses buang bulu.

\section{MATERI DAN METODA}

Bahan penelitian merupakan pasta kapur yang cara pengambilan contohnya dilakukan sebagai berikut:

Contoh diambil dari bak pembuatan pasta kapur yang berukuran panjang $x$ lebar $\times$ tinggi $=2 \mathrm{~m} \times 2 \mathrm{~m} \times 11 / 2 \mathrm{~m}$. Jumlah bak ada dua buah. Pasta kapur dalam air dibuat dengan cara memasukkan sejumlah kapur tohor dalam bentuk bongkah kedalam bak-bak dan kemudian ditambahkan sejumlah air;setelah selesai proses hidrasi terdapat pasta kapur dalam air dengan ketinggian ca $40 \mathrm{~cm}$ dari dasar bak. Pasta kapur terrendam air setinggi $20 \mathrm{~cm}$.Pengambilan contoh dilakukan dengan cara masing-masing bak diaduk dengan skop yang terbuat dari kayu,sehingga seluruh pasta teraduk dengan sempurna.Kemudian dari setiap bak diambil sejumlah contoh sebanyak ca. 3 kg.Contoh dikemas di dalam kantong plastik trasparan dan diberi ai sehingga pasta kapur terrendam sempurna.Kedua ncontoh diberi kode A dan lainnya B. Contoh-contoh kemudian dianalisa di Laboratorium PMNK BBKKP.Uji yang diminta oleh peneliti adalah : kadar air, $\mathrm{pH}$, oksida-oksida Kalsium, Magnesium, Aluminium, Besi, Silikat, Zat tak terlarut dalam asam klorida, kebasaan, Karbondioksida, kadar abu. Metoda analisa menggunakan cara-cara yang berlaku di BBKKP.Peneliti mengamati secara organoleptik keadaan contoh.

\section{HASIL PENELITIAN}

\section{Pengamatan visual/orgabnoleptis}

Sebelum diadakan penelitian secara laboratoris,peneliti terlebih dahulu mengadakan pengamatan secara visual/organoleptis keadaan kedua contoh dengan

Vol. XII No. 23 Th. 1996/1997 
hasil seperti tertera pada tabel 1.tentang pengamatan secara visual/organoleptis cntoh pasta kapur kode A dan B.

Tabel 1. Pengamatan visual/organoleptis contoh pasta kapur kode $\mathrm{A}$ dan $\mathrm{B}$

\begin{tabular}{|c|c|c|c|}
\hline no. & jenis uji & contoh A & contoh B \\
\hline 1. & Kenampakan & & \\
\hline 2. & $\begin{array}{l}\text { - warna } \\
\text { Keadaan }\end{array}$ & $\begin{array}{l}\text { Putih } \\
\text { homogen dan tak terasa }\end{array}$ & $\begin{array}{l}\text { Putih } \\
\text { Homogen dan tak terasa }\end{array}$ \\
\hline 3. & Bahan lain & $\begin{array}{l}\text { ada bagian yang keras. } \\
\text { Tak ternyata }\end{array}$ & $\begin{array}{l}\text { ada bagian yang keras. } \\
\text { Tak ternyata. }\end{array}$ \\
\hline
\end{tabular}

\section{Analisa kimia}

Analisa kimia atas kedua contoh dengan kode A dan B pasta kapur dalam air dilakukan di Laboratorium pada Seksi Pengawasan Mutu dan Normalisasi Barang Kulit. Balai Besar Penelitian dan Pengembangan Industri Barang Kuli kesuai permintaan Plastik. Jl. Sukonandi No. 9 Yogyakarta 55166. Analisa kimia sesuai permintaan dari peneliti.

enta tabel 2 tentang hasil uji kimiawi contoh pasta kapur dalam air, dibawah ini.

Tabel 2. Hasil uji kimiawi contoh pasta kapur * dengan kode $\mathrm{A}$ dan $\mathrm{B}$.

\begin{tabular}{|l|l|c|c|}
\hline no & jenis uii & contoh $\mathrm{A}$ & Contoh B \\
\hline 1. & Kalsium Oksida $(\mathrm{CaO})$ & $13,27 \%$ & $12,22 \%$ \\
2. & Magnesium Oksida $(\mathrm{MgO})$ & $13,27 \%$ & $14,00 \%$ \\
3. & Aluminium Oksida $\left(\mathrm{Al}_{2} \mathrm{O}_{3}\right)$ & & \\
& dan Besi Trioksida $\left(\mathrm{Fe}_{2} \mathrm{O}_{3}\right)$ & $0,60 \%$ & $0,83 \%$ \\
4. & Kadar air & $54,06 \%$ & $57,16 \%$ \\
5. & Silikon Dioksida $\left(\mathrm{SiO}_{2}\right)$ & $0,57 \%$ & $0,60 \%$ \\
6. & Zat tak larut dalam $\mathrm{HCL}_{4} \mathrm{~N}$ & $1,01 \%$ & $5,44 \%$ \\
7. & Kadar abu & $32,37 \%$ & $32,15 \%$ \\
8. & pH & 13,0 & 12,0 \\
9. & Kebebasan $\mathrm{HCl} \mathrm{0,5 \textrm {N }}$ & 32,62 & 28,55 \\
\hline
\end{tabular}

V. PEMBAHASAN Dari hasil penelitian dan pengamatan yang telah dilak komposisi kimia pasta

akan diadakan pembahasan hal-hal yang berk
*) dikoreksi dan disempurnakan dari data aslinya.

Majalah Barang Kulit, Karet dan Plastik kapur dan relevansinya untuk digunakan pada proses pengapuran kulit mentah; kemudian penelusuran terhadap bahan mentah yang digunakan untuk pembuatan pasta kapur; dan akhirnya kualitas pasta kapur. Keseluruhannya adalah tertuju pada kegunaan dalam industri penyamakan kulit dan khususnya proses pengapuran kulit mentah. Selanjutnya hal-hal tersebut diatas akan diuraikan seperti tertulis dibawah ini.

Sebagaimana telah terungkap pada hasil analisa kimiawi dari kedua contoh dengan kode A dan kode B yang tertera pada Tabel 2. tentang hasil uji kimiawi contoh pasta kapur, maka hasil rata-rata untuk Kalsium Oksida $(\mathrm{CaO})$ adalah $12.75 \%$ dan kadar Magnesium Oksida 15,81\% dari bahan basah. Kadar MgO jika dihitung atas bahan kering adalah sebesar $28,43 \%$. Hasil penelitian dari Wilson menunjukkan bahwa kandungan Magnesium Oksida (MgO) sampai 30\%, tidak menunjukkan adanya pengaruh dalam aplikasi teknis jika dibandingkan dengan penggunaan Kalsium Hidroksida murni, $\mathrm{Ca}(\mathrm{OH})_{2}$, untuk proses pengapuran. Tentang $\mathrm{pH}$ larutan pasta kapur tidaklah perlu dirisaukan, karena pada rentang yang tidak memungkinkan bekerjanya bakteri proteoletik. Rata-rata ph adalah 12,5 sesuai dengan $\mathrm{pH}$ dari larutan jenuh air kapur. Telah lazim pada pabrik penyamakan kulit maupun dibidang kegratan $\mathrm{R}+\mathrm{D}$, pada proses "liming" menggunakan $\mathrm{Ca}(\mathrm{OH})$, yang sebenarnya adalah total $\mathrm{Ca}+\mathrm{Mg}$ dihitung sebagai $\mathrm{Ca}(\mathrm{OH})_{2}$. Walaupun sampel tersebut adalah indikasi adanya sejumlah Magnesium Oksida kiranya perlu suatu survei mendalam tentang pengaruh kapur yang diperdagangkan akan kandungan Magnesium untuk meyakinkan penyamak. Unsur Besi yang terdapat dalam pasta kapur jika penggunaan pasta kapur sampai 5\%, sebagaimana dikerjakan di pabrik, maka akan terikutsertakan sebanyak ca 72,9 ppm Fe ${ }^{+3}$ tiap liter "float" setiap $100 \mathrm{~kg}$ kulit basah yang dikapur. Unsur Besi adalah merupakan pengganggu dalam proses penyamakan nabati, karena terbentuknya noda-noda, sehingga perlu adanya pengawasan proses penyamakan kulit.

Selanjutnya dilihat dari hasil analisa kimia akan dapat digunakan untuk menentukan asal usul bahan mentah yang digunakan dalam proses pembuatan kapur tohor. Kadar $\mathrm{MgO}$ dan $\mathrm{CaO}$; dan kadar $\mathrm{MgO}$ dan kadar $\mathrm{CaO}$ dapat dilihat pada tabel 3, tentang komparasi Dolomit dan pasta kapur seperti terlihat dibawah ini.

\section{Tabel 3. Komparasi Dolomit dan komposisi pasta kapur kode A dan B.}

\begin{tabular}{|l|l|c|c|}
\hline no. & unsur & $\begin{array}{c}\text { bantuan kapur } \\
\text { dolomit (\%) }\end{array}$ & $\begin{array}{c}\text { pasta kapur bahan } \\
\text { kering rata-rata (\%) }\end{array}$ \\
\hline 1. & $\mathrm{CaO}$ & 30,4 & 23,58 \\
2. & $\mathrm{MgO}$ & 21,9 & 29,25 \\
3. & $\mathrm{CaO}+\mathrm{MgO}$ & 52,3 & 52,83 \\
\hline
\end{tabular}


Dari tabel 3. tersebut maka pasta kapur yang dipergunakan untuk proses . pengapuran kulit mentah berasal dari batuan kesamaan diantara komposisi pasta kapur dengan komposisi batuan kapur dolomit. Dengan demikian anyak terdapat di Indonesia seperti Pegunungan kapur Kendeng Utara sampai ke Gresik adalah deposit batuan kapur dolomit. Bahan mentah yang digunakan untuk pembuatan pasta kapur dimana sampel berasal adalah dari lokasi tersebut diatas.

Mengingat hal-hal yang telah dibahas tersebut diatas maka peneliti an berasal dari pembakan batu kapur dolomit berpendapat bahwa kapur tohor supaya tidak berpengaruh terhadap mutu kulit jadi perlu diteliti pula kadar MgO, supaya tidak berih dari $30 \%$. Hasil (leather) yang diolah dari kuh men laboratorium PMNK BBKKP atas permintaan analisa kimia yang dilakukan oleh laboratorium peneliti terdapat pula unsur Fe $4 \mathrm{~N}$. Seperti halnya dinyatakan oleh Hansur-unsur mengandung unsur Kalsium ( $\mathrm{Ca}$ ) dan Mangan Valensi dua $\left(\mathrm{Mn}^{-2}\right)$, atau tersusun sebagai Seng $(\mathrm{Zn})$. Besi valensi dua ( $\left.\mathrm{Fe}^{-2}\right)$, Mangan $\left.\mathrm{Al}^{+3}\right)$ menurut peneliti adalah tidak terikat dengan $\mathrm{Ca}$ dan $\mathrm{Mg}$, karena gugus $\mathrm{R}$ 'biasany senyawa dolomit, sedangkan unsur Fe terikat sebagai $\mathrm{Ca}(\mathrm{Mg}, \mathrm{Fe})\left(\mathrm{CO}_{3}\right)_{2}$ dengan nama ankerit. Unsur Aluminium, Besi secara bersama-sama kedapatan dengan unsur Kalsiu dan Magnesium dibentuk dengan rumus molekul $(\mathrm{Ca}, \mathrm{Mg}, \mathrm{Fe})(\mathrm{Al}, \mathrm{Fe}) 2 \mathrm{SiO}_{6}$, in

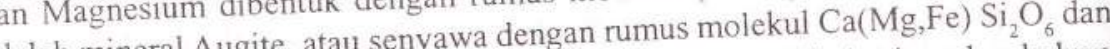
enis mineral ini termasuk grup Pyroxene.Peneliti menarik kesimpulan bahwa keberadaan unsur Besi dan Alumunium dalam contoh bukan terikat sebagai Augite taupun Pyroxene, melainkan kemungkinan besar adalah kotoran silikat yang berisi unsur $\mathrm{Al}$ dan $\mathrm{Fe}$.

Selanjutnya peneliti mengamati di lapangan bahwa sudah menjadi kebiasaan ngunaan selalu tidak memperhitungkan adanya unsur-unsur Magnesium yang seharusnya diketahui adanya batas kadar maksimum sebesar $30 \%$, demikian pula esi, dimana kedua unsur kimia dapat mempengaruhi mutu kulit yang disamak.

Mutu dari bahan kapur yang digunakan untuk proses pengapuran kulit mentah yang sampai saat ini belum diperhatikan dengan seksama, baik penggunaan pasta kapur maupun kapur mati (Hydrated lime) dalam bentuk curai perlu distadarkan. Paling tidak unsur Magnesium dan Besi. Khusus untuk yang berbentuk curai terkadang tercampur gumpalan-gumpalan yang membatu dan tidak larut dalam air sehingga dapat menimbulkan goresan-goresan pada kulit.

\section{KESIMPULAN DAN SARAN}

a. Berdasarkan analisa kimia, pH, konsistensi serta kadar Magnesium Oksida maka penggunaan pasta kapur dengan Kode A dan B cukup aman pada proses pengapuran kulit mentah.Kadar MgO sebesar 28,43\% adalah lebih kecil dari $30 \%$, namun sudah mendekati, selisih hanya $1,57 \%$ saja sehingga perlu diwaspadai.pH $=12,57 \%$,cukup baik untuk menahan pertumbuhan bakteri proteolitis, bahkan pada $\mathrm{pH}$ tersebut bakteri tidak tumbuh malahan mati total.

b. Pasta kapur yang digunakan untuk proses pengapuran kulit mentah baik yang berkode A maupun B. berasal dari hasil proses pembakaran batu kapur dolomit,dengan rumus kimia $\mathrm{CaCO}_{3} \mathrm{MgCO}_{3}$ atau $\mathrm{CaMg}\left(\mathrm{CO}_{3}\right)_{2}$. Pada batuan kapur dolomit $\mathrm{R}^{\prime \prime}$ adalah senyawa $\mathrm{CaCO}_{3} \mathrm{MgCO}_{3}$ sehingga unsur $\mathrm{Fe}$ dan $\mathrm{Al}$ adalah kotoran-kotoran silikat dan bukan mineral Augite atau batuan grup Pyroxene.

Pengertian penggunaan $\mathrm{Ca}(\mathrm{OH})$, secara kuantitatip dalam proses pengapuran buang bulu yang diperhitungkan atas berat kulit,ternyata sudah mencakup unsur Magnesium, jadi bukan $\mathrm{Ca}(\mathrm{OH})$, murni.

d. Adanya unsur Besi ( $\mathrm{Fe}$ ) dalam bahan kapur untuk proses pengapuran perlu diketahui, khususnya pada proses penyamakan kulit yang menggunakan zat penyamak nabati.

c. Pedoman tentang penggunaan pasta kapur atau curai seyogyanya perlu disusun. dengan mengadakan penelitian.

\section{UCAPAN TERIMA KASIH}

Terima kasih saya ucapkan kepada Yth.Ka BBKKP, khususnya Y th. Sdr.Djajusman dan Staf PMNK BBKKP atas bantuannya mengadakan pengujian atas sampel pasta kapur,dalam penelitian ini.

\section{DAFTAR PUSTAKA}

1. ADA PRINS Dr., "Qualitatieve Chemische Analyse", Scheltema \& Holkema N.V.Amsterdam 1952,7 de Geheel Herziene druk.

2. ASHFORD,TA. "An Introduction to the Physical Sciences", Holt, Rinehart and Wiston Inc. NY.,USA., 1960.

3. GNAMM H."Fachbuch für die Leder Industri" 4 Verbesserte

4. Herfeld.H.Dr.,Ing. "Grundlagen der Lederherstellung" Verlag von Theodor Steinkoff,Dresden und Leipzig, 1950

5. KUHL H. "Zement Chemie", Vlg.Chemie.,Berlin 1954

6. Mauthe G.Dr., "Chemie Fur Den Gerber ", Wissenschatliche Verlagsgesellschaft M.B.H.,Stuttgart, West Deutschand.

7. MIERS H.A."Minerralogy" Mac Millan and Co.,Ltd.ST. Martin's street, London 1939 
8. SHREVE "Chemical Process Industries" MgGraw-Hill., LTD., third edition 1967 9. Wilson J.A.,SC.,D." Modem Practice in Leather Manufactur". Reinhold Publishing Co., 1951.Usa., New York 